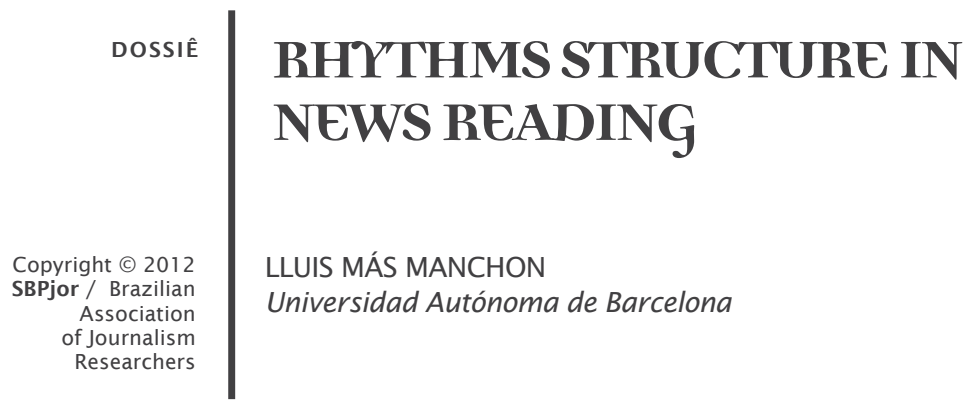

\begin{abstract}
Rhythm is of key importance to news casting in radio and television programs. This paper proposes a three level structure for rhythm in news discourse. It gives a comprehensive definition of rhythm and types of rhythm. Firstly, the Base Rhythm Structure consists of semantic and pragmatic rhythmic accents, coincident with very specific words. Secondly, these accents are grouped together according to type, frequency and order, thus configuring three types of "rhythmic units" (this is the Internal Rhythm Structure): starting, course and end units. A last structure level presents four discursive factors of the act, which are very important to integrate the overall time structure of news announcing (the Melodic Rhythm Structure). This integral structure for news announcing rhythm should be further tested in acoustic-experimental studies under the criterion of information transmission efficacy.
\end{abstract}

Keywords: Rhythm, Announcing, News, Discourse.

\title{
ESTRUTURA RÍTMICA NA LOCUÇÃO DE NOTÍ́CIAS
}

\section{Resumo}

O ritmo é muito importante na locução de noticias da radio e da televisão. Este artigo propõe uma estrutura rítmica em três níveis para este tipo de discurso. Da uma definição integral do ritmo e dos tipos de ritmos. Em primer lugar, a Estrutura Rítmica Base se compõe de acentos rítmicos semânticos e pragmáticos, coincidentes com palavras muito específicas. Em segundo lugar, estes acentos são agrupados segundo tipo, frequência e ordem, configurando três tipos de "unidades rítmicas" (esta é a Estrutura Rítmica Interna): unidades de começo, desenvolvimento e desenlace. Um último nível estrutural apresenta quatro fatores discursivos muito importantes para a integração geral da estrutura temporal da locução de notícias (a Estrutura Rítmica Melódica). Esta estrutura rítmica integral da enunciação de notícias deverá ser testada em estudos acústico-experimental tendo o critério da eficácia da transmissão de informação.

Palavras-chave: Ritmo, Locução, Notícias, Discurso.

\section{RHYTHM STRUCTURE IN NEWS READING}

\begin{abstract}
Resumen
El ritmo es muy importante en la locución de noticias en radio y televisión. Este artículo propone una estructura rítmica en tres niveles para este tipo de discurso. Da una definición integral de ritmo y de los tipos de ritmo. En primer lugar, la Estructura Rítmica Base se compone de acentos rítmicos semánticos y pragmáticos, coincidentes con palabras muy específicas. En segundo lugar, estos acentos son agrupados según tipo, frecuencia y orden, configurando tres tipos de "unidades rítmicas" (esta es la Estructura Rítmica Interna): unidades de comienzo, desarrollo y desenlace. Un último nivel estructural presenta cuatro factores discursivos muy importantes para la integración general de la estructura temporal de la locución de noticias (la Estructura Rítmica Melódica). Esta estructura rítmica integral para la enunciación de noticias deberá ser testeada en estudios acústico-experimentales bajo el criterio de la eficacia en la transmisión de información.
\end{abstract}

Palabras-clave: Ritmo, Locución, Noticias, Discurso. 


\section{INTRODUCTION}

Intonation refers to tone variations over time; that is: intonation is "rhythmic tone". Rhythm is then a cognitive activity caused by placement, order and synchronization of the tonal elements, especially the accents. In news reading, rhythm is as important as metrics in poetry or meter in music. Nevertheless, time has been barely researched and marginally considered in linguistics and only a few writing and speaking manuals have dealt with it (Rodero, 2003, Perona and Huertas, 2008, and Blanch and Lázaro, 2010). The situation is one in which the rhythmic criterion is apparent in the modulation of the vocal melody, or, at best, is attached to the chronology of speech. Of course, time has a lot to do with speech as the latter is ruled to a great extent by the duration of lexical and syntactic units; however, beyond these individual simple rhythmic events, there is a comprehensive rhythmic structure for the discourse:

Thus, as an intrinsic part of perception, tonal accents are in ways of attracting the receivers' attention. The following text can serve as an example:

\footnotetext{
"At that moment, the phone rang; something burning could be smelt all over the house, and the dog was running, desperately, through the entire house without knowing what to do. All this without realizing that it was all a dream, and dreams are just dreams" (Source: author).
}

Obviously, depending on how it is spoken, this very same text could be understood in very different ways. For example, it could be a little joke we make to some friends in a pub in a relaxing atmosphere by making them think that the fire had been real until the very end of the text. Another understanding would be possible if we changed a few of the more dramatic words, or even if just the context were different. In any case, what is really important to make it "credible", whatever the discourse, is the prosody of speaking, basically based on the different tonal accents and pauses placed in the text. Note the following text, where tonal accents are placed on keywords (in CAPITAL LETTERS), and pauses can be of different durations between word groupings (signaled in ascending order with /, // and ///):

"At THAT moment/ the phone RANG// something BURNING could be smelt all over the house/ and the dog was running// DESPERATELY/ through the entire house without knowing WHAT to do/// All this WITHOUT realizing that/ it was all a DREAM// and dreams are just 
DREAMS ...///".

From the point of view of communication efficacy, the enunciation of the first text would not be credible and would even make little sense. In fact, our friends could think we were reciting some literary work - different discourse, different praxis-, while the second text reading would immediately catch their interest and provoke reactions to its content, according to our communication objectives - our friends would immediately think that our house did catch fire. The differences between the first and second text lie in the comprehensive structure of the speaking rhythm, which does its work in the practical sphere of discourse.

In the second text, it is easy to process the key accents: "that", "rang", "burning", "desperately", "what", etc., as well as the different fragments bounded by the "///", "//" and "/". In fact, in a spoken text as strict as a news cast, processing depends upon the flow of expressive information, which creates a structure of attention calls during the message by means of a timely arrangement of the most interesting points:

\footnotetext{
"Constancy, order and proportionality would be the features highlighted in the first theories of rhythm [...]. Those first theories defined it as a periodic succession in time; as was proposed for poetry by Gili Gaya (1956: 7) when he referred to the 'repetition of certain events in time" (Rodero, 2003: 191).
}

A structure based on different tonal accents, grouped in units, which are different according to the whole structure of the news text, is what we are looking for. So then, how can we measure this "time structure" for news reading? What are the laws and properties that rule it? What are those "time events" in the case of news casting? How are they organized, ordered and what types are there? In this paper, we try to give an answer to all those questions, starting from a review of knowledge about rhythm in general (mainly focusing on Fraisse, 1967 and 1974), and a compilation of knowledge about rhythm in the news enunciation according to authors like Perona (1992), Huertas and Perona (1999 and 2008), Rodríguez Bravo (1984 and 1989), Balsebre (1987) or Rodero (2003). This is a descriptive study that brings together the results of different pieces of research, and that finally proposes a hypothetical comprehensive rhythmic structure for the spoken piece of news that should be tested in further acoustic-experimental studies.

So, first of all, there is a revision of the concept of rhythm and the related perception principles. With these criteria in hand, the piece of news is analyzed in two discursive levels (van Dijk, 1990): micro 
linguistic (morphology and syntaxes) and macro linguistic (semantics and pragmatics). From this analysis, a three layer structure is proposed: base structure ("time or rhythmic accents"), the internal structure ("time or rhythmic units") and the melodic structure ("overall timing or rhythm of discourse").

\section{Concept of Rhythm \\ Types of Rhythm}

In general terms, experts distinguish between endogenous and exogenous rhythms (Fraisse, 1974, 1967). Endogenous rhythms are endemic to human beings and can be irrational -like heart beats, breathing, sleeping, eating, etc. - or rational -states of mind, vital activity, human intents and purposes (work, walks, daily routines, etc.). On the other hand, exogenous rhythms vary according to the environment. They are the wide range of time events that surround us every day and hour as a result of external stimuli of all sorts: nature, society, abstract reality, culture.

Nevertheless, as perception is structural itself (gestaltic), that is, it arranges reality (the environment) according to physiological states and states of mind, the exogenous rhythms are necessarily hybrids. For instance, when a professor teaches a history lesson, he should present the theme according to human sense which thinks of history as a progressive continuum in time associated to the lesson's timing. So what the professor says "first" is going to be assumed as having happened "first"; and that is the result of a half endogenous (natural) half exogenous (acquired) process. In fact, as what is purely natural or congenital to the professor and student (exclusively endogenous) is always taking place unconsciously, it is only when speaking of exogenous processes that we can consider the task of the professor (as a communicator) to be good or bad, as he will have to adapt himself to the current determinants in class: age, intellectual level, and attention level of students, year, season, month and time of the class, etc. Now let us substitute "professor" by "news announcer".

In this case, the rhythm in communication processes should include this integration of exogenous and (pseudo exogenous) endogenous rhythms in the framework of the communication act's function. We are going to see, for example, the influence of the rhythm of the type of language -type of sentences, words, syllables, etc.-, the influence of emotional rhythms -sadness drives a slow rhythm, happiness 
drives a vigorous rhythm with verve in the discourse, or the influence of content-dependent rhythms -topics, keywords...- on the media news announcement.

To begin with, news reading is slightly influenced by emotional rhythms, as retransmitting a dramatic event with a very sad ending is not the same as announcing a football score or some election results. The spokesman or presenter can never entirely avoid a certain empathy with the significance of the information being transmitted (Rodríguez Bravo, 1984). For instance, in a context of serious economic crisis, with news programs always showing the bad economic situation, would not it be communicatively important if the presenter about to finally read about a positive economic event did this with a slight degree of happiness and excitement? Obviously, there would be an "emotional accent" to emphasize that it is a piece of good news in an overall context of bad ones. Furthermore, economics is such a complex theme for the audience to understand that the newsreader would probably be satisfied if viewers "understood" that the theme is "economics", the subtheme is "unemployment" and the "news" about it was "good news".

So, it is not possible to distinguish between purely endogenous and purely exogenous rhythms. We must therefore turn to the message as the only source of rhythm to be investigated. Furthermore, the analysis of the message (media news enunciation) is be governed by three fundamental perceptual principles.

\section{Rhythmic Principles}

The most important perceptual principle for rhythm is the anticipation of rhythmic elements. The feeling of expecting the next "beat" is what helps to apprehend reality -as it becomes expected. According to the Theory of Gestalt, perception pursues prediction, that is to say, confirmation of the "anticipation hypothesis" that the person constantly generates when interacting with the environment. Certainly, human beings have survived thanks to the anticipation of dangerous stimuli from the environment. As keeping all five senses constantly on the alert and analyzing reality as if it were all entirely unknown is absolutely wearying and unsustainable, the human defence mechanism applies its organization of reality according to rhythmic patterns, so that it becomes expected and any dangerous situation can readily be noticed because it breaks with these patterns: the passage of time, customs of animals, cars passing by a motorway, or just clouds drifting by in the sky. 
In other words, these rhythmic patterns allow humans to focus on really important stimuli: a lion's roar, the screeching of a car's brakes, a black cloud or a scream (or a tonal peak in a keyword)-, and so he/she will have a better chance of surviving.

The second principle is precisely related to different types of rhythm. As has been seen, everything can have a rhythmic pattern, but not everything can be perceived as such at the same time. The principle that should be respected for the different rhythms to be perceived simultaneously is that of comprehensive perceptive coherence. In fact, the discrimination of different stimuli units (rhythms), and, as a consequence, that of their intervals, is explained by the Gestalt Psychology Laws especially the similarity and contrast laws. These two laws refer to the grouping of stimuli by their "similarity" and "contrast" with other stimuli. In the spoken language, with stimuli that not only communicate through their form but also through their content, these laws also apply to the semantics and pragmatics of discourse. By grouping rhythmic elements coherently according to their similarity and contrast, attention is focused on a whole meaningful structure of discourse. Thus, many phonemes go unnoticed when perception groups them to form a word, and the same happens with many words when they are grouped to form a sentence, and so on. It is not difficult to imagine a structure in different layers, whereby form and content are integrated "rhythmically".

In fact, those layers emerge thanks to the third principle: rhythmic synchrony. Synchrony is the human capacity to put together different elements to form another one that belongs to a "higher" layer, which, in turn, can be put together with elements of that layer and form another one at an even higher layer. Unlike similarity and contrast laws, synchrony makes lower-level elements to be still perceived as individuals at the same time as they are perceived as part of a whole. So, the complex process of announcing news -a text to be read as if it were not written-, must synchronize rhythmic (lexical, syntactic, semantic, pragmatic and acoustic) elements to control its efficacy.

The more these three principles are present, either as endogenous or exogenous rhythms, the greater the rhythmic structuring of the spoken piece of news will be.

\section{Base Rhythm Structure in News Announcing}

The Base Rhythm Structure of news reading defines the primary rhythmic stimuli: the Rhythmic Elements and the Rhythmic Accents. The 
former define the absolute rhythmic rate in speaking; the latter refer, in perceptual terms, to the attention calls, and it is the basis for the superior structure (Internal Rhythm Structure). This accentuation has four main properties: content, tone, intensity and duration. All four are related. In fact, the stress is produced using tone (pitch), intensity and duration (Maekawa, 2003, Ladd, 1993) and also with the use of "content words" (keywords) that, in turn, tend to last more than the "functional ones", and are more likely to be stressed (Greenberg et al., 2002, Geumann, 2002, Batliner et al, 2001).

To define the "rhythmic elements" and "rhythmic accents", a revision of the "dimensions of discourse signification" (van Dijk, 1990) is needed:

1. Micro linguistic dimension (rhythmic elements): phonological, morphological and syntactical aspects.

2. Macro discursive dimension (rhythmic accents): semantics and pragmatics.

\section{The Micro linguistic dimension: rhythmic elements}

The tonal peaks depend upon the sonority generated by vowels in general and some specific consonants $(d, m, n)$. Therefore, the levels of sonority (pitch) depend upon the spectrum stability of the phoneme, which is only achieved with clear and precise diction, and which takes a minimal duration to articulate. This is why a phoneme articulated in a different manner than the previous vowel tends to increase its duration (Buff, 1985: 67). These are some of the most important connections between duration and type of vowels and consonants in Spanish:

Vowels are longer if followed by a voiced consonant, and even more so if they belong to the same syllable.

. The closed vowel "u" is shorter than the "a". And the anterior "e" is shorter than the posterior "o".

- The fricatives are longer than the plosive. The "rr" is one of the longest and the " $r$ " is one of the shortest.

- The intervocalic position of a consonant after a stressed vowel makes the syllable very long (e. g. "paso").

Beyond these linguistic variables, syllables are of compulsory articulation. In fact, Fraisse (1974) compares syllables to music notes -semiquaver, quaver, crotchet, minim..., which shows the importance he gives to the syllable as a fundamental rhythmic element in speaking. Also, most authors use it to measure the announcer's pace -amount of 
syllables articulated per minute (Rodríguez Bravo, 1984, Liu and Wang, 1998, and Liu et al., 2001). In this sense, considering that in syllabic languages every word has got one, and only one stressed syllable, they become the key rhythmic element in TV and radio news reading in Spanish (and also in Catalan and Portuguese) and are the basis for semantic and pragmatic accents. That being said, we are now in a position to define the "micro linguistic accent" as:

1. "number of syllables per time unit"; and

2. "duration of each syllable".

In the previous example (false fire alarm), the word "desperately" [desesperadamente in the original] has a morphology -seven long and steady syllables with pre-eminence of the phoneme "e" -that "drives the receiver to despair". The rest of accents in the text were monosyllabic and two-syllable words. Moreover, there is an alternation of vowels in the row of syllables, which makes diction and pitch modulations much easier.

So, first, syllables can be used to measure rhythm in news reading: it has been established that the neutral rhythm in news reading has as many syllables per minute as heart beats for a normal person, that is, around 70 syllables per minute. With this, news announcers have a reference to consider the overall rhythmic pace of their announcing.

Secondly, a syllable is stressed through pitch or intensity peaks, and duration and those parameters are used to stress syllables in general (rhythmic element) and, also, some specific syllables in important words: rhythmic accents.

\section{The Macro discursive dimension: rhythmic accents}

Now that we know the basic rhythmic elements of speaking, it is time to define the basic rhythmic accents. As has been said before, pitch, intensity and duration are the acoustic parameters to stress spoken language (Van Santen, 2003: 241). However, for them to constitute a rhythmic accent, they should be placed on semantic and/or pragmatic accents (Mas Manchón, 2008).

\section{The semantic accent}

The semantic accent is the content being referred to by one or more words, which can become a keyword to be stressed. As mentioned above, the way to stress a keyword is by increasing duration, intensity 
and pitch on this stressed syllable.

Basically, in the first place, there is a naturalistic semantic accentuation that serves as an initial criterion on which to base the rhythmic patterns for the news announcement that is associated to the kind of "movement" suggested by the concept being referred to. For example, in the previous example (again, the false fire alarm), the word "desperately" becomes a "base rhythm stimulus" because of its morphology and also because of the semantic value of the referent ("desperately" = the fast pace of someone who is "desperate"), and that is why the reader stresses it when reading the text. Thus, slow rhythms are associated to the semantics of "approaching" and "slow pace", and fast rhythms with "growing distance" and "fast pace". Negative words are pronounced with inharmonious, deep, slow and constant tones, whereas positive words are harmonious and with a steady timbre. The words referencing fast movements imply a fast diction and high tones, and those referencing slow movements imply slow diction and low tones. Therefore, a proper use of semantic stresses can create new timings for the storytelling, coherent with the nature of what is being said. For instance, transmitting news about a game of golf is not the same as news about an exciting football game result, and reporting on a friendly match is not the same as reporting on a world championship final.

In second place, the themes exposed in a discourse are also a source of help in deciding where to place the stress of the semantic accent (Mas Manchón, 2006). The way themes like economics or politics, arts and culture, scientific inventions or sports are announced are very different from one another and the pace will be altered too according to whether the events concerning those themes are more or less urgent and dramatic or just eventual, because categories of information and the semantics of discourse determine the stressing and the attention calls to viewers to ensure they fully understand the news.

To sum up, the semantic accent can be "referential" (natural characteristics of the reality being communicated) or "theme-based" (a more conventional way of referencing news topics).

\section{The pragmatic accent}

Rhythmic accents can also be caused by the structure of discourse (the praxis) being expressed. They may change according to whether it is an action-based discourse, a character-based discourse, or a "fact-based discourse" like news. Even in a genre as heavily based 
on semantics as poetry -full of personal feelings and sensations-, the rhythm of the act (pragmatics) is always present besides each poem's specific content (semantics).

News programs can be broken down into five parts: phrases, paragraphs, announcements, reports and piece of news. All of them have pauses in between and have their own rhythms. In general, they are fast and constant in studio and slow and variable in location shots. The integration of the two layers is shown by pauses, which not only separate pragmatic units, but also give time for the processing of semantic accents (Balsebre, 1994: 204). Let's see how those pragmatic accents are.

News reading in TV and radio is a discourse based upon "transmission of 'new' information about a topic". As said before, the semantic accent refers to topics (themes), about which something "new" happened. This newness is the pragmatic accent. And according to journalism theories, there is widespread agreement about the 6 W's of news: what, who, when, where, why and how. The order of appearance of keywords responding to these "W's" determines their importance the reason for the theme to become "news" ("rheme") (Valldubí and Vilkuna, 1998).

So the accent in news reading is semantic and pragmatic. It is placed in a word with three or four syllables and preferably with "a" and "e" vowels, which becomes a keyword because it:

(1) Belongs to certain topic and has some sense (positive, negative, urgent, dramatic...),

(2) And/or transmits new information as it announces one or more "W's": e.g. a "victory" (what) of "Obama" (who), "yesterday" (when), etc.;

and will be marked by an increase in pitch, intensity and duration of the stressed syllable. These rhythmic accents are also named "prominences".

Those are the "notes" of the song. Now we need to find the timing (rhythmic unit) to associate those rhythmic accents in discourse.

\section{Internal Rhythm Structure in News Announcing}

News reading is characterized by short and direct statements at a fast, emphatic and constant pace:

"La frase reúne tempo, acento, unidades melódicas, grupos fónicos y pausas en un mismo planteamiento tensivo o energético: 'la frase enunciativa consta regularmente de una parte tensiva y otra distensiva. La primera, prótasis, estimula y reclama la atención; la segunda, apódosis, completa el pensamiento respondiendo al interés suscitado' (Navarro, 1974: 40)" (Rodríguez, 1984: 170). 
Previous rhythmical accents are integrated in rhythmic units that can be different along the discourse. In general, at the beginning of the piece of news, units are long, rhythm is fast, accents are high (Wichmann et al., 1997) and pauses are short and periodic. Next, the rhythmic unit in the course of the piece of news implies a "narrative" style, with slower constant rhythms, accents more spread out, and longer pauses in between rhythmic units (Garner, 1970, and Garner and Gottwald, 1968). At the end of the piece of news, rhythm becomes irregular, at a slower pace and with more pauses (Zimba y Robin, 1998); some great tonal peaks are placed at the very end before the final slowing down.

Therefore, the internal structure of news reading rhythm is given by the organization of three types of rhythmic units -beginning, course and end-characterized by the organization of the rhythmic accents. They normally last from 5 to 7 seconds, enough time to modulate a sentence (approximately 25 syllables), but not so much time as to lose viewer's attention (Fraisse, 1967: 99).

Accents and pauses are the main time events, which dimension, order and frequency distinguish the three rhythm units (Fernández de la Torriente, 1975, and Kerbrat-Orecchioni, 1977, cited in Perona, 1992, and Rodríguez Bravo, 1984). These units make up the internal structure of the piece of news. Generally, for the three types of rhythmic units, a pragmatic accent marks the start of the unit after a pause, and then semantic accents are placed periodically. While the frequency of semantic accents is dependent on the type of unit (as is shown next), the order depends upon the following criteria:

Temporal criterion: what happens first is placed first.

Logical criterion: the cause goes first than the consequence. In news language, we usually announce the "who", then the "what", the "where", "how" and "why".

- Cultural criterion: subject-verb-predicate.

- Harmonic criterion: the rhythm for the rhythm is purely musical and "aesthetic".

Now, it is time to see those three types of rhythmic units in the three main phases of the piece of news: beginning, course and end. It is important to notice that the typical units are repeated several times within the phase they belong to. In the first place, this is a typical rhythm unit for the beginning of the spoken piece of news:

1. The newsreader begins with the most relevant information -one or two pragmatic accents; then, gradually and in 
downtrend, some semantic accents are placed.

2. He slows down because the articulatory strength is now weak, and so rhythmic accents are done with longer syllables in keywords, and with some eventual little pauses called resets (Rodero, 2003: 217):

(a) Potential resets: short and expressive pause, and with previous syllables in suspension (e.g. "The immigrants / do not want to leave Algeciras").

(b) Explicative resets: pause that refers to content, also short and part of the pitch modulation (e.g. "The king Don Juan Carlos / visibly moved / turned up this morning for..." It also separates phonic groups.

3. This unit has a high absolute rhythm to capture receiver's interest.

4. Pause: long pause at the end of the rhythmic unit, which serves to breathe, separate different units' contents and plan the following modulation; it should be of at least 0.5 seconds.

In the second place, this would be a typical rhythmic unit for the course of the piece of news:

1. Plateau: fragment dominated by the rhythmic elements (syllabic) without many rhythmic accents.

2. However, there are some pragmatic and semantic accents to mark some eventual and periodic key information (keywords).

3. It has a medium absolute rhythm to maintain the receiver's interest.

4. This structure is repeated along the course of the piece of news, although at the end of the phase, the rhythmic unit increases its ratio of rhythmic accents until a steady $3 / 4$ rate, that is to say, a rhythmic accent (keyword) every four rhythmic elements.

In third and last place, this would be a typical rhythmic unit for the end of the piece of news:

1. The previous $3 / 4$ rhythmic accents rate turns into an uptrend of rhythmic accents.

2. Overall, the unit presents a plateau plus a great accent at the end.

3. A typical slow absolute rhythm turns little by little into an absolute rhythm of crescendo. 
4. Pragmatic accents are scarce now, and only a few semantic accents show up. The uptrend ends up with a last and great semantic accent, right before coda.

5. Coda: progressive slowing down of rhythmic elements until the final pause (Kurematsu et al., 2001).

6. Silent: pause amongst paragraphs or enunciations, greater than one second (Rodero, 2003). It has a "contextual" meaning.

Obviously, there are many other factors that influence these rhythm units, but always within the theoretical framework proposed here. So, the internal structure is flexible, in the sense that accents can vary in type, frequency and order. In fact, the Melodic Rhythm Structure we are about to see takes those "factors" as part of the structure in order to avoid the same old news reading song, which is what actually happens when there is no strategic reading based on a theoretical prosodic structure; this happens when accents are placed "randomly" and attention is addressed to non-relevant information (Rodríguez Bravo, 1984).

\section{Melodic Rhythm Structure in News Announcing}

So, the typical rhythmic units for the beginning, course and end of the piece of news are influenced by some time factors of the act of communication itself. Altogether, they make up the Melodic Rhythm Structure in News Announcing.

This structure integrates and complements all inferior levels -rhythmic elements, semantic and pragmatic accents, and rhythmic units- taking into account the overall strategy of news discourse (Rodríguez Bravo, 1984, Balsebre, 1987, and Perona, 1992).

This strategy is represented by four communication factors: phases of discourse, intention of the emitter, communication context and reception conditions:

1. Phases of the piece of news as a discourse are determined by:

(a) Articulation: faster at the beginning of speech because of the articulatory strength.

(b) Culture: on one hand, every start is related to courage, dynamism and will..., while every final is related to gradual decrease and extinction. On the other hand, the longer the pause the greater the sensation of end; in fact, the longer the pause the 
faster the starting modulation of the next item will be (Charadeau, 1984: 43).

(c) Processing: attention is greater at the beginning of a speech, because the receiver is fresh and expectant; and it is also quite high at the end of it as it is the "last effort" -and last chance- the receiver has to fully understand by then.

2. Newsreader intention is ruled by four simultaneous objectives:

(a) Transmit information: the key for information processing is attention and understanding. Attention should focus on relevant information, so understanding can happen.

(b) Entertainment: to make information interesting, it is important to create expectations by distributing the relevant information periodically over the discourse.

(c) Manipulation: presenters should give the impression that what they say is a window to reality through a resolute, decisive and convinced rhythm.

(d) Subjectivity:

Speaker movements: in the news reading at studio, distractions should be diminished; that's why the talking head has been maintained through the years, and that is why any movement of the talking head (with hands/arms or facial muscles) is always intended to be neutral and constant.

- Speaker's psychological movements: the speaker has some involvement with the content transmitted, and expresses it with the semantic accent.

3. Communication context: the knowledge the audience has of the information transmitted should be considered.

4. Reception conditions: the presenter is constantly trying to catch his/her attention with a fast, constant and emphatic rhythm at the beginning, an "unexpected" accents following and a final attention call to the coda.

These four factors affect the arrangement of the different rhythmic units and create the general rhythmic structure for TV and radio news announcing, and the specific rhythmic features for the different topics, events, styles and, as it turns out, news as a whole. 


\section{Discussion and Implications}

This is the summary of the Rhythmic Structure for News Reading: The "Starting Rhythmic Unit" is typified by a high absolute rhythm, periodic accents placed on keywords, emphatic timing, downtrends and resets. The "Course Rhythmic Unit" is characterized by medium absolute rhythms, accents (isolated, distanced and periodic), pauses, and plateau. The "Final Rhythmic Unit" is marked by slow and decreasing rhythms, eventual accents, and more of the three types of pauses with longer durations, plus a great final accent and coda.

In the previous pages, a deep dissertation on rhythm in news speaking has been carried out. Basically, it has been shown that:

1. There is a meaningful structure of rhythm in news reading dependent on the type of act, the theme, and the new and relevant information.

2. This rhythmic structure has two main communication dimensions:

(a) "Perceptual dimension": to fulfil the function of a communication process, we need to arrange the distribution of the attention points along the message (using rhythmic parameters) so that understanding is facilitated.

(b) "Productive dimension": a trained newsreader must conduct the communication function within the limitations of his or her articulatory rhythmic possibilities. As rhythm is fully communicative, a strategic planning of it is of key importance.

3. The rhythmic structure of the piece of news belongs to the prosodic structure of the discourse, which is mainly characterized by the accent. More precisely, the accent is the rhythmic element that sets the rhythmic units, depending on its frequency, type and order.

We have come up with these conclusions after revising all factors that influence speaking rhythm in human communication, mass communication, news communication and spoken communication.

To sum up, the rhythmic unit is composed of accents produced in different discursive levels (syllabic, semantic and pragmatic), which serve to distinguish the rhythmic units in the three main phases of the news discourse. Plus, these three units are put together according to four news discourse factors to be taken into account -such as the 
announcer's intention and subjectivity, the context of the process or the reception conditions of viewers. So the final rhythmic (melodic) structure of news casting has two subjacent layers: the internal rhythm structure (rhythmic units) and the base rhythm structure (rhythmic accents). All three integrate comprehensively within the limits of the three perceptual rhythmic principles: anticipation, coherence and synchrony.

Thus, a typical national-politics/economics piece of news would have a set of essential thematic words (e.g. congress, president, crisis, banks, minister, politics...) and a set of news keywords (e.g. package of measures, more credit, public funds...). From there on, taking advantage of the sonority and duration of these words' phonemes (con-GRESS, CRIsIs, miNISter, creDIT...) and the use of different types of pauses (to mark the pragmatic or semantic stress, and to separate units), the three rhythmic units arise along the reading. First, the starting unit presents the urgent and important information ("More credit...") and the thematic context of it in downtrend ("...for banks..."); and again: pragmatic accent ("... This is the package of measures...") and thematic accent ("...the president has presented in the congress"), and again: ("... Public funds will be used to face the crisis"). Then, the course unit tells the details with a plateau and constant rhythm, and some periodic accents on more specific and accurate keywords (e.g. negotiations, bankers, liquid assets, mortgages...). Finally, the end unit makes a final inflexion with a slow rhythm to the end and a great prominence in e.g. "financial crisis". Obviously, the whole structure is determined by the "context" of the act (speakers' intention to communicate more or less drama plus receiver's slight interest to understand), the type of discourse (the "most current" news) and the phases (drama, action and climax that turns into a "momentary" end).

In future work, the Melodic Rhythmic Structure of News Announcing should be tested in different acoustic-experimental studies, so that we can model it. This is a fertile field for the textual analysis of the piece of news according to genres, themes and styles. For now, the model proposed can be helpful for the theory and practice of announcing and writing subjects. Later on, a prosodic model will be important for the improvement of virtual presenters through more sophisticated algorithms. Lastly, we consider this approach can be applied to other communication processes, like advertising discourse, character construction, politicians' public speeches, oratory and reciting, etc.; or even to speech therapy and speaking disorders. 


\section{REFERENCES}

BALSEBRE TORROJA, Armand. EI Lenguaje radiofónico. Madrid: Cátedra, 1994.

BALSEBRE TORROJA, Armand. Las imágenes auditivas en la radio. [S.I. : s.n.], 1987.

BATLINER, A.; N?TH, E.; BUCKOW, J.; HUBER, R.; WARNKE, V.; NIEMANN, H. Duration Features in Prosodic Classification: Why Normalization Comes Second, and what they Really Encode. In: Congress Prosody in Speech Recognition and Understanding. Molly Pitcher Inn, Red Bank, NJ, USA, October 22-24, 2001. [Online]. URL: http//www.isca-speech.org/archive, consulted June 13, 2010.

BLANCH, Margarita; LÁZARO, Patricia. Aula de locución. Madrid: Signo e Imagen, 2010.

BUFF, Robert. La mise en relief acoustique Dans le français radiophonique. Thése à la faculté des lettres de l'Université de Zurich. ADAG. Administration et Druck, AG, Zurich, 1985.

CHARAUDEAU, Patrick. El discurso de la información: la construcción del espejo social. Barcelona: Gedisa, 2003

CHARAUDEAU, P Patrick (1983). Langage et discours: éléments de sémiolinguistique: théorie et pratique. Paris: Hachette, cop.

FRAISSE Paul. Psychologie du rythme. Paris: Presses universitaires de France (PUF), 1974.

FRAISSE, Paul. Psychologie du temps. Paris : Presses universitaires de France, 1967.

GARNER, W. R. Sensation and perception. Visual Perception, 1970.

GARNER, W. R.;GOTTWALD, R.. The perception and learning of temporal patterns. In: Quarterly Journal of Experimental Psychology, vol. 20, pp. 97-109, 1968.

GREENBERG, S.; CARVEY, H.; HITCHCOCK, L.; CHANG, S. Time frames of spoken language. In: ITRW on Temporal Integration in the Perception of Speech Aix-en-Provence. France, 8-10 April, 2002. 
[Online]. ISCA archive. URL: http//www.isca-speech.org/archive, consulted October 17, 2007.

GEUMANN, A. Segmental durations in loud speech. In: ITRW on Temporal Integration in the Perception of Speech Aix-en-Provence. France, 8-10 April, 2002. [Online]. ISCA archive. URL: http//www.iscaspeech.org/archive, consulted October 17, 2007.

HUERTAS, Amparo; PERONA, Juanjo. Redacción y locución en medios audiovisuales. Barcelona: Bosch, 1999.

LIU, Z., HUANG, J. Y WANG, Y. (2001). Classification of TV programs based on audio information using hidden markov model. En: IEEE Signal Processing Society Workshop on Multimedia Signal Processing. [Online]. URL: http://ieeexplore.ieee.org/stamp/stamp. jsp?arnumber $=00738908$, consulted June 16, 2010.

LIU, Z.; WANG, Y. Audio Feature Extraction and Analysis for Scene Segmentation and Classification. In: Journal of VLSI Signal Processing, vol. 20, pp. 61-79, 1998. Kluser Academic Publishers. [Online]. URL: http://vision.poly.edu:8080/paper/jvsp98.pdf, última consulta el 16 de junio de 2010.

MAEKAWA, K. Corpus of Spontaneous Japanese: Its design and evaluation. In: Proceedings of the ISCA and IEEE Workshop on Spontaneous Speech Processing and Recognition (SSPR2003), pp. 7-12. Tokyo, Japan, 2003.

MAS MANCHÓN, Lluís. Formas Entonativas en las fases del Discurso Noticia. En: Actas "XXXII Congresso Brasileiro de Ciências da Comunicação". Curitiba, (PR, Brasil), del 4 al 7 de septiembre, 2009. [Online]. URL: http://www.intercom.org.br/papers/nacionais/2009/ lista_area_DT1-TE.htm, consulted January 26, 2011.

MAS MANCHÓN, Lluís. Creación de un inventario de palabrasclave para la identificación temática de noticias de televisión en catalán. Tesina. Depósito del Laicom, Edifici I, UAB, Bellaterra, Barcelona, 2006.

MORALES, Fernando; MAS MANCHÓN, Lluís. Estructura semántica e impresión emocional del overlapping o encabalgamiento con función expresiva. In: Zer, vol. 14, n ${ }^{\circ}$ 27, pp. 125-147, 2009. Universidad del País Vasco.

NAVARRO TOMÁS, Tomás. Manual de entonación española. Madrid: Guadarrama, 1974.

PERONA PÁEZ, Juanjo; HUERTAS BAILÉN, Amparo. Redacción y locución en medios audiovisuales: la radio. Barcelona: Bosch, 2008. 
PERONA PÁEZ, Juanjo. El ritmo en la expresión radiofónica. Tesis Doctoral. Departament de Comunicación Audiovisual i Publicitat. UAB, 1992.

RODERO ANTÓN, Emma. Locución radiofónica. Madrid: Instituto Oficial de Radio y Televisión, 2003.

RODRÍGUEZ BRAVO, Àngel. La construcción de una voz radiofónica. Tesis doctoral: Facultad de Ciencias de la Información de la Universidad Autónoma de Barcelona, 1989.

RODRÍGUEZ BRAVO, Àngel. La voz en la radio (Manipulaciones y técnicas de expresión). Tesina. Depósito del Laicom, Edifici I, UAB, Bellaterra, Barcelona, 1984.

VALLDUBí, E.; VILKUNA, M.. On rheme and kontrast. In: Syntax and Semantincs, 29: 79-108, 1998.

VAN DIJK, Teun . La noticia como discurso: comprensión, estructura y producción de la información. Barcelona: Paidós, 1990.

VAN SANTEN, Jan. Segmental duration and speech timing. In: Computing prosody, Cambridge, Massachusetts, 2003.

WICHMANN, A.; HOUSE, J.; RIETVELD, T. Peak Displacement and Topic Structure. In: Conference "Intonation: Theory, Models, and Applications". Athens. Greece. September 18-20, 1997. ISCA ARCHIVE. [Online]. URL: http://www.isca-speech.org/archive, consulted March 15, 2008.

ZIMBA, L.D.; ROBIN, D.A. The effects of varying signal intensity on the perceptual organization of rhythmic auditory patterns. In: The National Center of Voice and Speech. University of lowa, 1998. [Online]. URL: http://www.ncbi.nlm.nih.gov/pubmed/10491700, consulted June 16, 2010. 
RHYTHMS STRUCTURE IN NEWS READING

BRAZILIANJOURNALISM RESEARCH -Volume 8-number z- zOIa| 29 